\section{Comparison of Epidural Anaesthesia and General Anaesthesia with Caudal Epidural Analgesia for Minimally Invasive Lumbosacral Spine Surgeries}

\section{Abstract}

Background: Minimally invasive lumbar spine surgeries have become popular due to less tissue trauma involved and reduced hospital stay. General anaesthesia is more frequently used for these surgeries, though regional anaesthesia is proved to be safe in few studies.

Purpose: To test the efficacy of Epidural anaesthesia (EA) for these lumbosacral spine surgeries in comparison with General anaesthesia supplemented with caudal analgesia (GA).

Method: We randomized 80 patients posted for elective primary minimally invasive lumbosacral decompression spinal procedures into two groups of 40 each. The GA group patients received caudal analgesia with Ropivocaine $0.2 \% 30$ $\mathrm{ml}$ with Buprenorphine $75 \mathrm{mcg}$ before incision. The EA group patients received $10 \mathrm{cc}$ of Ropivocaine $0.75 \%$ bolus with Buprenorphine $75 \mathrm{mcg}$ through epidural catheter placed two spaces above the surgical incision site. Both groups received IV Paracetamol 1 gm $6^{\text {th }}$ hrly and rescue analgesics given were IV Diclofenac and Tramadol.

Outcome measures: We compared the groups for perioperative haemodynamic variables, anaesthesia and surgical time, postoperative analgesic requirement, PONV and length of hospital stay.

Results: Intraoperative hypotension was seen more in GA group. The surgical and anaesthesia duration were significantly less in EA group. However, the patients for two level discectomies ( 3 vs. 1) and bilateral laminoforaminotomies ( 8 vs. 4) were more in GA group. Postoperative analgesic requirement was significantly more in GA group. There was no significant difference in the PONV and all patients were discharged on the first postoperative day.

Conclusion: Epidural anaesthesia can safely replace GA for minimally invasive lumbar spine procedures. It not only avoids the risks of GA, but also the intraoperative blood loss, the duration of anaesthesia and the postoperative IV analgesic requirements are much less with the use of Epidural anaesthesia.

Keywords: Minimally invasive spine surgeries; Epidural anaesthesia; Caudal analgesia; Ropivacaine

\section{Geetha}

Lakshminarasimhaiah, Rajashree Madabhushi and Kulyadi Raghavendra Pai

\section{Department of Neuroanaesthesia and}

Neurocritical Care, Ramaiah Institute of Neurosciences, M S Ramaiah Medical College and Hospitals, Bengaluru, Karnataka, India

Corresponding author:

Dr. Geetha Lakshminarasimhaiah

” geetha4kiran@yahoo.in

Associate Professor, Department of Neuroanaesthesia and Neurocritical Care, Ramaiah Institute of Neurosciences, M S Ramaiah Medical College and Hospitals, Bengaluru, Karnataka, India.

Tel: +91-9611897899

Citation: Lakshminarasimhaiah G, Madabhushi R, Pai KR (2018) Comparison of Epidural Anaesthesia and General Anaesthesia with Caudal Epidural Analgesia for Minimally Invasive Lumbosacral Spine Surgeries. Int J Anesth Pain Med. Vol.4 No.1:3 


\section{Introduction}

General anaesthesia has been the most commonly used anaesthetic technique for lumbar spine procedures. The caudal epidural analgesia used in combination with GA has been excellent in managing postoperative pain in these patients. Epidural anaesthesia is another alternative technique. It avoids GA related complications like aspiration, postop nausea and vomiting and probably shortens the OR time.

The minimally invasive lumbar spine procedures are becoming more popular because of the less tissue trauma involved. With the advances in these techniques there is reduction in operative times, perioperative morbidity and they allow faster ambulation [1]. This nature of minimally invasive procedures necessitates anaesthesia technique that allows faster recovery and facilitates the early discharge of the patients from hospital.

Hence, we conducted a prospective randomised study comparing the intraoperative variables, postoperative complications, safety and efficacy of Epidural anaesthesia and General anaesthesia with caudal analgesia for elective minimally invasive lumbar spine procedures.

\section{Materials and Methods}

After obtaining the project approval from the institutional review board, the written-informed consent was prepared for the patients being enrolled for elective lumbar spine procedures. 80 patients between $18-70$ years of either sex belonging to ASA physical status I - III with $\mathrm{BMI}<35$ undergoing primary elective minimally invasive lumbosacral one or two level discectomies, unilateral or bilateral laminoforaminotomies were included for this study. These patients were divided into two equal groups in a Randomized fashion and they received Epidural Anaesthesia alone (EA) or General anaesthesia (GA) with caudal epidural analgesia.

Patient refusal for regional anaesthesia alone, any bleeding disorder or patient on anticoagulants, previous spine surgeries in the area intended for epidural catheter insertion history of allergy to local anaesthetics and local infection at the injection site were the exclusion criteria.

In GA group, patients were premedicated with Glycopyrolate for antisialogogue effect. They were given normal saline $10 \mathrm{ml} /$ $\mathrm{kg}$ intravenously $15 \mathrm{~min}$ before induction. GA was induced with Fentanyl $2 \mathrm{mcg} / \mathrm{kg}$, Propofol $2 \mathrm{mg} / \mathrm{kg}$, Vecuronium $0.1 \mathrm{mg} / \mathrm{kg}$ followed by endotracheal intubation. Patients were positioned prone for caudal analgesia with $30 \mathrm{ml}$ of $0.2 \%$ Ropivocaine with Buprenorphine $75 \mathrm{mcg}$ under $\mathrm{C}$-arm guidance. On completion of the surgery, muscle relaxation was reversed and trachea was extubated. All patients were monitored in PACU.

In EA group, patients were preloaded with $10 \mathrm{ml} / \mathrm{kg}$ of normal saline. Epidural anaesthesia was performed in sitting position at least two spaces higher than the surgical incision site, with $18 \mathrm{G}$ Touhy needle (B-Braun) and catheter was advanced $5 \mathrm{~cm}$ into the epidural space in cephalad direction. After confirming no aspirate in the catheter, 3 cc of $2 \%$ Lignocaine with adrenaline 1:2 lac was used as test dose. Once the negative test was elicited for CSF and blood, 10 cc of $0.75 \%$ Ropivocaine with Buprenorphine $75 \mathrm{mcg}$ was given epidurally and the catheter was secured. Patients were made to lie down supine, and sensory blockade with pin prick and motor blockade were assessed with modified Bromage score $5 \mathrm{~min}$ after the epidural bolus, every $2 \mathrm{~min}$. Once the adequate sensory and motor blockade was achieved, patients were positioned prone with the help of bolsters to keep the abdomen free. Once the patients felt the position was comfortable, Dexmedetomedine infusion at $0.25 \mathrm{mcg} / \mathrm{kg} / \mathrm{hr}$ IV for sedation was started. They were started with Ropivocaine $0.2 \%$ at $10 \mathrm{ml} /$ hr epidurally, one hour after the epidural bolus if the surgery extended beyond an hour. Bladder was not catheterized in any of these patients.

Inadequate sensory and motor blockade beyond $30 \mathrm{~min}$ following the Epidural induction were considered as unsuccessful block. These patients were given GA and such patients were excluded from the study.

In both the groups, after the induction of anaesthesia, hemodynamic variables were monitored every $5 \mathrm{~min}$ till the end of the surgical procedure. Episodes of hypotension, hypertension, bradycardia and tachycardia, $20 \%$ beyond the preoperative value) were noted. Hypotension of SBP below $90 \mathrm{~mm}$ of $\mathrm{Hg}$ was treated with boluses of IV Ephedrine $6 \mathrm{mg}$. inadequate analgesia was treated with boluses of Fentanyl $25 \mathrm{mcg}$. Total dose of Ephedrine and Fentanyl were recorded. All 80 patients were given Dexamethasone $16 \mathrm{mg}$ before the surgery started.

The intraoperative data collected were Induction to incision time, total duration of anaesthesia, total duration of surgery, blood loss as $<50 \mathrm{ml}, 50-100 \mathrm{ml}$ or $>100 \mathrm{ml}$. All these procedures were performed by the same surgeon and his opinion on operative conditions in terms of motor blockade and bleeding at the operative site were noted. And the same anaesthetist was present for all the patients.

Postoperatively, the parameters assessed were visual analogue scale for pain, incidence of nausea and vomiting. Intravenous paracetamol 1 gram was given $8^{\text {th }}$ hourly for the first 24 hours post operatively in both the groups. Intramuscular tramadol $50 \mathrm{mg}$ was given as rescue analgesic if VAS $>3$. Post-operative nausea and vomiting was treated with Ondensetron $4 \mathrm{mg}$ IV and Metoclopromide $10 \mathrm{mg}$ IV.

\section{Modified Bromage scale \\ Grade Definition \\ $0 \quad$ No motor block \\ 1 Inability to move raised leg, able to move knees and feet \\ 2 Inability to move raised leg and knees, able to move feet completer motor block of lower limb}

The analgesic requirement during $24 \mathrm{hr}$ postop period was recorded. 


\section{Statistical analysis}

Two sets of 40 unique numbers were created using the software research randomiser to randomise patients into epidural group or GA with caudal analgesia group.

Descriptive and inferential statistical analyses were carried out. Results on continuous measurements were presented on Mean $\pm \mathrm{SD}$ and results on categorical measurements were presented in Number (\%). Significance was assessed at $5 \%$ level of significance. Inter group analysis on metric parameters was done using Student $t$ test. Chi-square/ Fisher Exact test was used to find the significance of study parameters on categorical scale. $P$ value: $P \leq 0.01$ was suggestive of strongly significant parameters. The Statistical software namely SAS 9.2, SPSS 15.0, Stata 10.1, MedCalc 9.0.1,Systat 12.0 and $R$ environment ver.2.11.1 were used for the analysis of the data.

\section{Results and Observations}

There were a total of 80 patients enrolled for this study after randomization, with mean age of $45.9 \mathrm{yr}$ in GA group and 40.9 $\mathrm{yr}$ in EA group. The samples were gender matched with $\mathrm{p}$ value of 0.370 , however there were more male patients in GA group (57.5\%) and female patients were more in EA group (52.5\%). GA group had 15 smokers and there were 11 smokers in EA group. The average height of patients was $158.8 \mathrm{~cm}$ in GA group vs. $159.9 \mathrm{~cm}$ in EA group. The samples were weight matched with $p$ value of 0.885 (Table 1).

The Epidural catheters were placed in single attempts at L1-2 or T12-L1 interspaces. There were no dural punctures or surgical interferences in any patients. No patients had epidural failure requiring $\mathrm{GA}$.

Intraoperative hypotension was more seen in GA with Caudal analgesia group with $p$ value of 0.050 and they required more Ephedrine with $p$ value of 0.010 (Table 2). There were no patients requiring Atropine for low heart rates in both the groups.

The onset of sensory blockade was tested with pinprick at the lower lumbar and lumbosacral operative site. The average time for onset of sensory blockade was $4.30 \mathrm{~min}$ and the motor blockade was $16.9 \mathrm{~min}$. 22 patients had sensory level up to T10, 15 patients had T8 level and 3 patients had T6 level. The average Bromage score was 1.55 (Table 5). The duration of sensory blockade varied from 3 to $4.5 \mathrm{hr}$ and motor blockade was found to be varying from 1.5 to $2.5 \mathrm{hr}$.

Duration of anaesthesia was significantly lesser in EA group with an average of $102.90 \mathrm{~min}$ and it was $154.15 \mathrm{~min}$ in GA group (Table 3). Similar trend was seen with the duration of surgery, however more patients in GA group had bilateral laminoforaminotomy in GA group ( 8 vs. 4) and two level discectomies (3 vs. 1). Intraoperative blood loss was more seen in GA group with $p$ value of 0.130 (Tables 4). The same surgeon performed all these procedures and was satisfied with the anaesthetic technique in both the groups.

Postoperative VAS was assessed. There was no statistical difference between the two groups with respect to VAS recorded
Table 1 Comparison of demographic data between the two groups.

\begin{tabular}{|c|c|c|c|c|c|}
\hline & Mean age & Gender & Weight & Height & Smokers \\
\hline EA & $40.30 \pm 13.26$ & $\begin{array}{r}\text { Male 19 } \\
\text { Female 21 }\end{array}$ & 61.75 & 159.9 & 11 \\
\hline GA with CE & $45.90 \pm 13.87$ & $\begin{array}{r}\text { Male 23 } \\
\text { Female 17 }\end{array}$ & 61.45 & 158.8 & 15 \\
\hline
\end{tabular}

Table 2 Intraoperative hypotension and requirement of Ephedrine.

\begin{tabular}{|c|c|c|c|c|}
\hline & Hypotension & \multicolumn{3}{|c|}{ Ephedrine requirement } \\
\hline EA & $8(20 \%)$ & $5(12.5 \%)$ & $3(7.5 \%)$ & 0 \\
\hline GA with CE & $16(40 \%)$ & $2(5.0 \%)$ & $13(32.5 \%)$ & $1(2.5 \%)$ \\
\hline P=0.010* & & & & \\
\hline
\end{tabular}

Table 3 Comparison of times and intervals.

\begin{tabular}{|c|c|c|}
\hline & Surgery time & Anaesthesia time \\
\hline EA & $82.88 \pm 41.85$ & $102.90 \pm 42.17$ \\
\hline GA with CE & $115.05 \pm 53.51$ & $154.15 \pm 46.18$ \\
\hline P value & $0.004^{* *}$ & $<0.001^{* *}$ \\
\hline
\end{tabular}

Table 4 Intraoperative blood loss.

\begin{tabular}{|c|c|c|c|}
\hline & $<50 \mathrm{ml}$ & $50-100 \mathrm{ml}$ & $>100 \mathrm{ml}$ \\
\hline EA & $31(77.5 \%)$ & $9(22.5 \%)$ & $0(0 \%)$ \\
\hline $\mathrm{P}=0.130$ & $24(60 \%)$ & $14(35 \%)$ & $2(5 \%)$ \\
\hline
\end{tabular}

Table 5 Sensory block onset / Motor block onset (in minutes) and bromage score in EA group.

\begin{tabular}{|c|c|}
\hline Vensory block onset (minutes) & $4.30 \pm 1.67$ \\
\hline Motor block onset (minutes) & $16.90 \pm 5.54$ \\
\hline Bromage score & $1.55 \pm 0.50$ \\
\hline
\end{tabular}

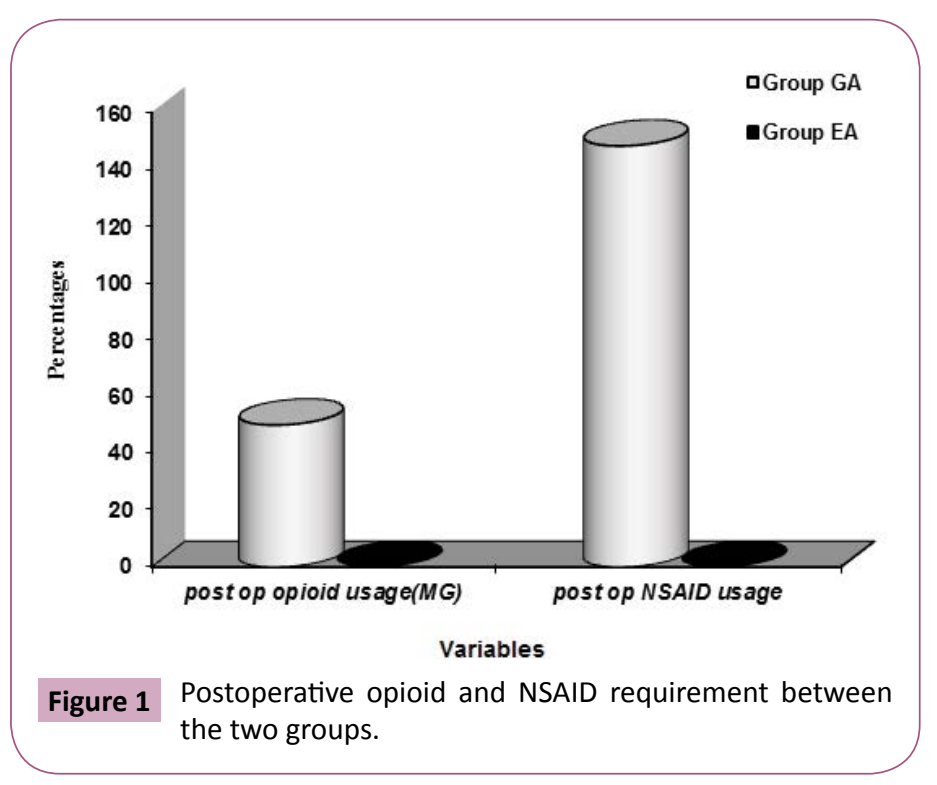

in the PACU. But no one in EA group required rescue analgesic in the first $24 \mathrm{hr}$ post op period other than paracetamol $1 \mathrm{G}^{\text {th }}$ hourly as per the protocol. In GA with CE group, 30\% required Tramadol and Diclofenac was given as rescue analgesic in all 40 
patients (Figure 1). Post op nausea was noted in $5 \%$ and vomiting was observed in $2.5 \%$ of GA with CE patients. There was no occurrence of PONV in EA patients. All patients were able to ambulate on the same day of surgery and were discharged within $48 \mathrm{hrs}$ of surgery.

\section{Discussion}

Minimally invasive technology has evolved rapidly over the years for lumbar spine decompression and stabilization procedures. In these techniques, surgeons use smaller retractor systems to access the spine with less tissue trauma. Most of these systems have tubular dilators which are first inserted to gently separate rather than cut the muscles. Since these techniques cause less local pain, the perioperative analgesic requirement is reduced [1].

Both General anaesthesia and Regional anaesthesia have been used for these procedures. Pre-emptive Caudal epidural analgesia to supplement intraoperative and post-operative analgesia has been described along with General Anaesthesia. It significantly reduces the post-operative NSAID requirement [2].

Epidural anaesthesia has been used as an alternative to general anaesthesia for lumbar spine procedures. Elias. C. Papadaulos et al [3] compared EA and GA for lumbar microdiscectomies. Lignocaine $(20-30 \mathrm{cc})$ with $100 \mathrm{mcg}$ Fentanyl was used for Epidural anaesthesia. They did not find any difference between the two groups with respect to surgical time, VAS score, hospital stay, ambulation on the day of surgery or cardiopulmonary complications. But epidural patients had significantly less nausea and vomiting. The EA group patients received lignocaine with fentanyl. In our study, the duration of anaesthesia was significantly lesser in EA group with an average of $102.90 \mathrm{~min}$ and it was 154.15 min in GA with CE group. The post-operative VAS scores were higher in GA with CE group.

Epidural Anaesthesia was demonstrated superior to General Anaesthesia in reducing surgical times and blood loss while providing equal or superior intraoperative hemodynamics in a study conducted by Demirel et al. [4] they also found that EA improves immediate postoperative outcomes by providing more stable hemodynamic conditions and less pain with its concomitant need for postoperative analgesics and their associated adverse side effect of nausea.

Ropivacaine is a new amide local anaesthetic with a structure closely related to bupivacaine, the butyl group being replaced by a propyl group. Ropivacaine is approximately $50 \%$ less cardiotoxic than bupivacaine and possesses a greater safety margin between convulsant and lethal doses. Its shorter systemic half-life makes repeated doses potentially safer. It is also known that when ropivocaine is used less than $0.375 \%$, it causes predominantly sensory blockade and very minimal motor blockade [5].

Opioids added to epidural anaesthesia hasten the onset of block. A study by Cherng et al. [6] on epidural administration of the mixture of $100 \mathrm{mcg}$ fentanyl and $1 \%$ ropivacaine solution accelerated the onset of sensory and motor blocks for knee arthroscopic procedures. They found that onset time of sensory block to the T10 dermatome was $13.0+/-3.0 \mathrm{~min}$ and the onset of motor block up to Bromage scale 1 and 2 were found to be $11.9+/-4.6$ and $24.4+/-5.9 \mathrm{~min}$. In our study, the average time for onset of sensory blockade with $0.75 \%$ ropivocaine with 75 mcg of Buprenorphine was $4.30 \mathrm{~min}$ and the motor blockade was $16.9 \mathrm{~min}$. We recorded the time of onset of sensory blockade at the surgical incision site which was L4-5 or L5-S1 in most of the cases.

Guler et al. [7] compared 3 doses of ropivacaine for epidural anaesthesia in the patients undergoing transurethral surgery and transurethral resection of prostate or bladder tumours. They noted $55 \%$ of patients achieving sensory level of T6 with $0.75 \%$ group. In our study $55 \%$ of patients reached only T10 level. The occurrence of bradycardia and hypotension in their study was more frequent. The difference probably is due to the higher volume $(15 \mathrm{ml})$ used and the lithotomy position.

In a retrospective study, lower injectable narcotic requirements, incidence of postoperative urinary retention and lower operative blood loss for patients receiving epidural anaesthesia was found by Greenbarg et al. [8]. Even in our study, the EA group had less intraoperative blood less.

Sedation plays an important role in patient comfort during procedures under regional anaesthesia. It gives the comfort to the anaesthetist as well if the patient's respiration is not affected. In patients receiving Dexmeditomedine infusion during epidural anaesthesia for inguinal herniorraphy, Celik et al. [9] showed that dexmeditomedine provided stable sedation, haemodynamics and respiration. This observation was similar to our study in EA group with Dexmedetomedine sedation.

Rodgers et al. [10], reviewed the results from randomised trials estimating the postoperative mortality and morbidity with epidural or spinal anaesthesia. They found that neuraxial blockade reduces all cause mortality and serious postoperative complications, supporting more widespread use of neuraxial blockade. Mortality was reduced by one third in patients allocated to neuraxial blockade. It also reduced the risk of deep vein thrombosis, pulmonary embolism, transfusion requirements, pneumonia, respiratory depression, myocardial infarction, and renal failure.

Regional anaesthesia is not only a safe and highly tolerable technique but also gives the surgeon the ability to contact verbally with the patient for assessing the adequacy of the decompression. In addition, because these operations are usually performed in the prone position, the awake patients can selfposition to avoid nerve injury to the brachial plexus and pressure necrosis to the face, which may occur in the malpositioned patient under GA [11].

Surgeons typically focus on the issue of maximizing the operative room efficiency. Regional anaesthesia plays an important role in solving this problem. Firstly, regional anaesthesia can be safely induced in the preoperative room so that the OR times can be minimized. Secondly, many studies on spine surgeries under regional anaesthesia including ours, conclude that duration of anaesthesia is less with regional anaesthesia when compared to $\mathrm{GA}$. All these help in reducing the waiting times for the surgery [12]. 


\section{Limitations of the Study}

The only limitation of this study was more patients of bilateral laminoforaminotomies and two level discectomies belonged to GA with caudal epidural group even after randomisation.

\section{Conclusion}

Epidural anaesthesia can safely replace GA for these minimally

\section{References}

1 Slosar PJ (2010) Minimally Invasive Spine Surgery: An Evolution in Progress. The Journal of the Spinal Research Foundation 5:26-31.

2 Saoud A, Elkabarity R, Abdellatif A (2012) Efficacy of Preemptive Caudal Analgesia in Single Level Lumbar Spine Decompression and Fusion Surgery. World Spinal Column Journal 3:71-79.

3 Papadopoulos EC, Girardi FP, Sama A, Pappou IP, Urban MK, et al. (2006) Lumbar microdiscectomy under epidural anaesthesia: a comparison study. Spine J 6:561-564.

4 Demirel CB, Kalayci M, Ozkocak I, Altunkaya H, Ozer Y, Acikgoz BA (2003) Prospective Randomized Study comparing Perioperative Outcome Variables After Epidural or General Anesthesia for Lumbar Disc Surgery. J Neurosurg Anesthesiol 15:3.

5 Gaurav Kuthiala, Geeta Chaudhary (2011) A review of its pharmacology and clinical use. Indian J Anaesth 55:104-110.

6 Cherng CH, Yang CP, Wong CS (2005) Epidural fentanyl speeds the invasive lumbosacral spine procedures. In addition to avoiding the risks of GA, the intraoperative blood loss, the duration of anaesthesia and the postoperative IV analgesic requirements are much less with the use of Epidural anaesthesia.

\section{Disclosures}

Funding and Support: Nil

Conflict of interest: Nil

onset of sensory and motor blocks during epidural ropivocaine anaesthesia. Anesth Analg 101:1834-1837.

7 Guler G, Aksu R, Dogru K, Sofikerim M, Tosun Z, et al. (2009) Comparison of 3 doses of ropivacaine for epidural anesthesia in transurethral surgery. Saudi Med J 30:67-71.

8 Greenbarg PE, Brown MD, Pallares VS, Tompkins JS, Mann NH (1988) Epidural anesthesia for lumbar spine surgery. 1:139-43.

9 Celik M, Koltka N, Cevik B, Baba H (2008) Intraoperative Sedation during Epidural Anesthesia: Dexmedetomidine Vs Midazolam. The Internet Journal of Anesthesiology 17:2.

10 Rodgers A, Walker N, Schug S, McKee A, Kehlet H, et al. (2000) Reduction of postoperative mortality and morbidity with epidural or spinal anaesthesia: results from overview of randomised trials. BMJ 321:16.

11 Smreka M, Baudysolvam O, Juran V, Vidlak M, Gal R, et al. (2001) Lumbar disc surgery in regional anaesthesia: 40 years of experience. Acta Neurochir 143:377-81.

12 Vishal Moudgil, B.S. Bajwa (2014) Lumbar Spine Surgery Outcome: Effect of Regional Anaesthesia. Global Journal of Medical Research 14:4. 